\title{
Delayed Granulomas after Filler Injection in an Immunosuppressed Patient: A Case Report
}

\author{
Tae Ho Kim, Seok Joo Kang, \\ Eui Han Chung, Hook Sun \\ Department of Plastic and Reconstructive \\ Surgery, Inje University Busan Paik \\ Hospital, Inje University School of \\ Medicine, Busan, Korea
}

No potential conflict of interest relevant to this article was reported.
Recently, dermal fillers have been used with increasing frequency to improve facial contours for cosmetic purposes. The appreciable increase in such filler procedures has led to more adverse events and complications. Herein, we report the clinical significance and differential diagnosis of delayed multiple granulomas that occurred in a patient with a history of an injection of an unknown substance as a filler 20 years previously. She was also taking oral steroids and tacrolimus for immune suppression after a kidney transplant that she received 10 years before she presented with granulomas.

Keywords Dermal fillers, Granuloma foreign-body, Immunosuppression

\section{INTRODUCTION}

Rhinoplasty using fillers to improve the shape of the soft tissues has become popular because of its relative simplicity and fast recovery time. However, the increased use of filler injections has led to more complications. Filler injection-related complications may occur immediately or within a few days, but in some cases, the onset may be delayed for several years $[1,2]$. Immediate complications include redness, swelling, bruising, and pain, and early complications include infection, hypersensitivity, skin discoloration, vascular occlusion, and contour instability. Foreign body granuloma (FBG) reaction is a prime example of a delayed complication [3].

According to a recent study, the prevalence of FBG was found to be $0.02 \%$ to $0.4 \%$ after hyaluronic acid injections, and $0.04 \%$ to $0.3 \%$ after bovine collagen injections [4]. Unlike immediate or early complications, late or delayed complications, including FBG, present with non-specific symptoms such as pain. Generally, the most common reasons for a patient to seek care are palpable subcutaneous nodules, swelling, and deformation in the treated area.

Received: Mar 13, 2018 Revised: Apr 14, 2018 Accepted: Apr 19, 2018 Correspondence: Seok Joo Kang Department of Plastic and Reconstructive Surgery, Busan Baik Hospital, Inje University School of Medicine, 75 Bokjiro, Busanjin-gu, Busan 47392, Korea. E-mail: sonydr@naver.com

Copyright $\odot 2018$ The Korean Society for Aesthetic Plastic Surgery.

This is an Open Access article distributed under the terms of the Creative Commons Attribution Non-Commercial License (http://creativecommons.org/licenses/by-nc/4.0/) which permits unrestricted non-commercial use, distribution, and reproduction in any medium, provided the original work is properly cited. $\quad w w w . e-a a p s . o r g$

\section{CASE REPORT}

A 35-year-old woman had received an injection of an unknown substance in her nose for cosmetic purposes 20 years ago. During the month prior to her admission, she developed multiple irregular subcutaneous masses that were palpable around the glabellar area. Subsequently, she was admitted to our hospital for the chief complaint of these masses increasing in size and expanding to a wider area. The patient's medical history included a kidney transplant 10 years ago, and she had been taking prednisolone ( $5 \mathrm{mg}$, by mouth) and tacrolimus ( $0.25 \mathrm{mg}$ twice a day, by mouth) since then.

Facial computed tomography performed after admission (Fig. 1) showed multiple small, well-defined hypodense masses to the left of the glabella and on both sides of the nose. In addition, multiple small masses were found in the bilateral buccal spaces, cheeks, and chin (Fig. 2).

In accordance with the patient's desire to undergo a cosmetic rhinoplasty at the same time, the lesions that could be visually identified were removed by open rhinoplasty and skin incisions around the glabella, under general anesthesia. The multiple masses found inside the nasal area during the detachment process following the open rhinoplasty were round and measured $<5 \mathrm{~mm}$, and severe adhesions with the surrounding soft tissues were found. The masses were composed of a white and soft lumpy foreign substance. The same pattern was observed for the masses around the glabella (Fig. 3, 4).

We decided to follow up the multiple masses in the bilateral buccal spaces and chin since they were small and not easily accessible. 


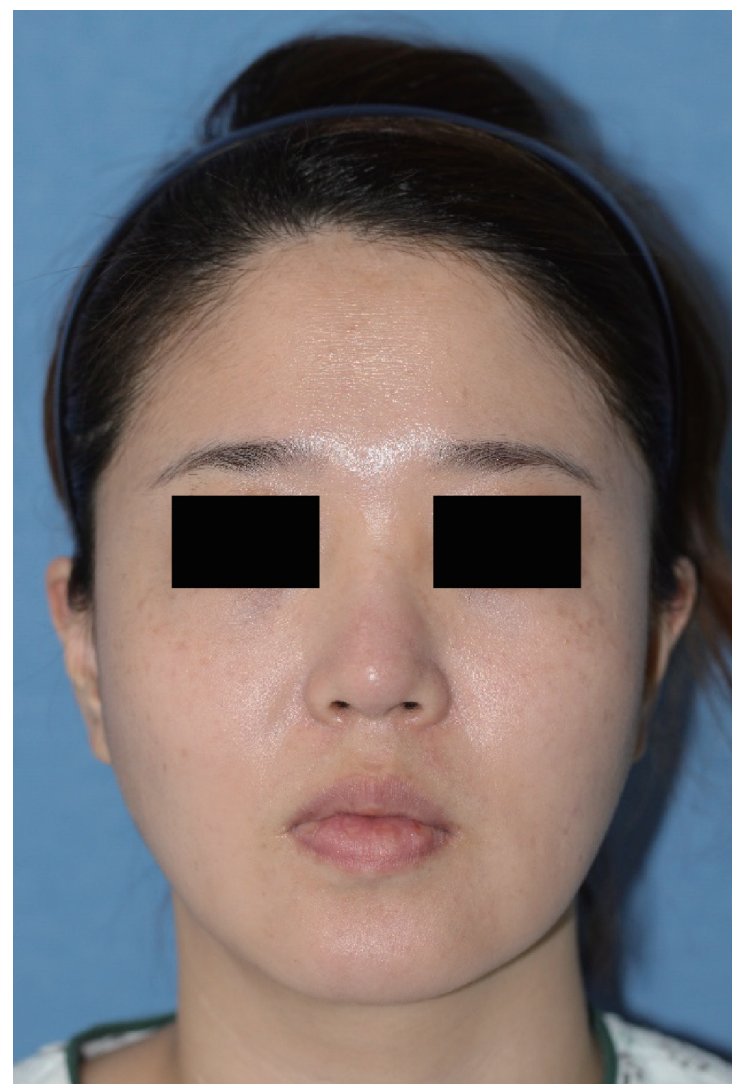

Fig. 1. Photograph showing multiple subcutaneous nodules around the nose and glabella.

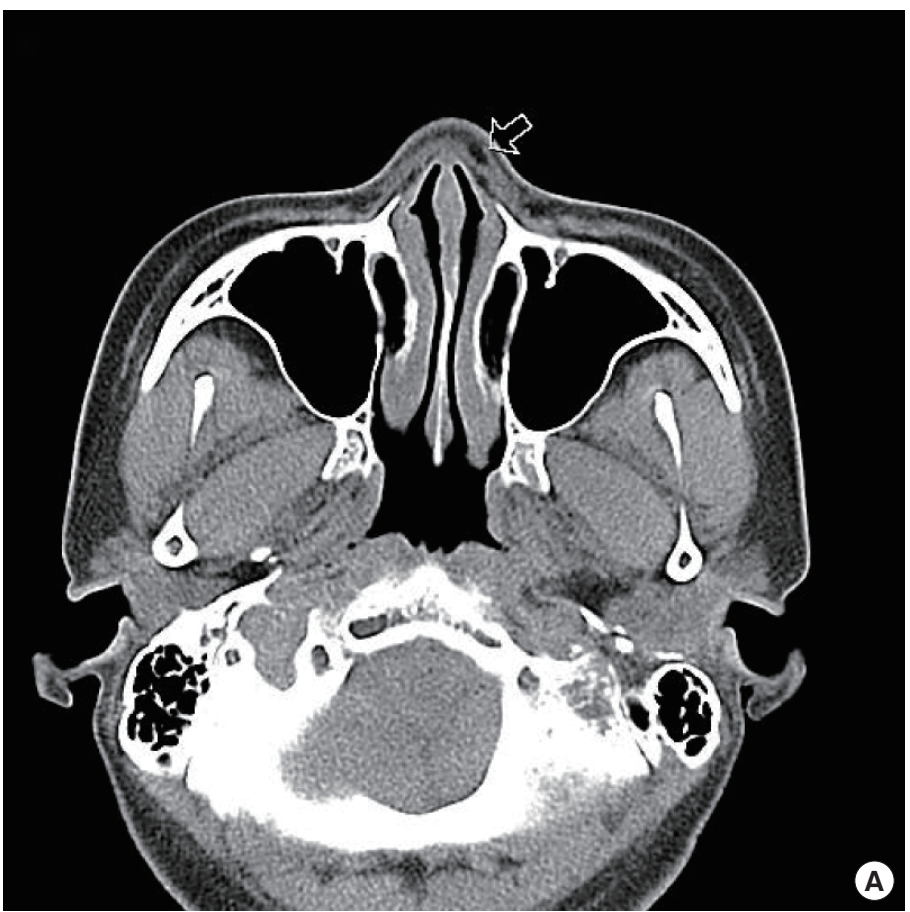

Histopathologic analysis of the biopsy performed of the removed lesions showed a hyaline collagenous wall accompanied by FBG (Fig. 5). The pathologic findings showed a cyst of granulomas with a center that was empty of tissue, and macrophages were also empty of foreign substances. It was presumed that the fat necrosis was caused by the foreign substances injected into the patient. This was also considered to be why the masses seen on facial bone computed tomography appeared hypodense.

\section{DISCUSSION}

Steroids inhibit fibroblastic activity, collagen deposition, macrophage activity, and giant cell formation [5], while immunosuppressants act selectively on T-cells to inhibit interleukin 2 and interferon gamma production by $\mathrm{T}$ helper cells, which inhibit the formation of granulomas [6]. Accordingly, steroids and immunosuppressants are often used as therapeutic agents for autoimmune diseases, such as Crohn disease.

According to an existing study, FBG may appear at any time between 5 months and 15 years [1]. FBG occurred 20 years after a filler injection procedure in our patient, which is later than has been reported in previous studies. The patient had been taking prednisolone ( $5 \mathrm{mg}$, by mouth) and tacrolimus $(0.25 \mathrm{mg}$ twice a day, by mouth) since her kidney transplant 10 years earlier. The continuous use of steroids and immunosuppressants may have delayed the formation of the granulomas beyond the previously pub-

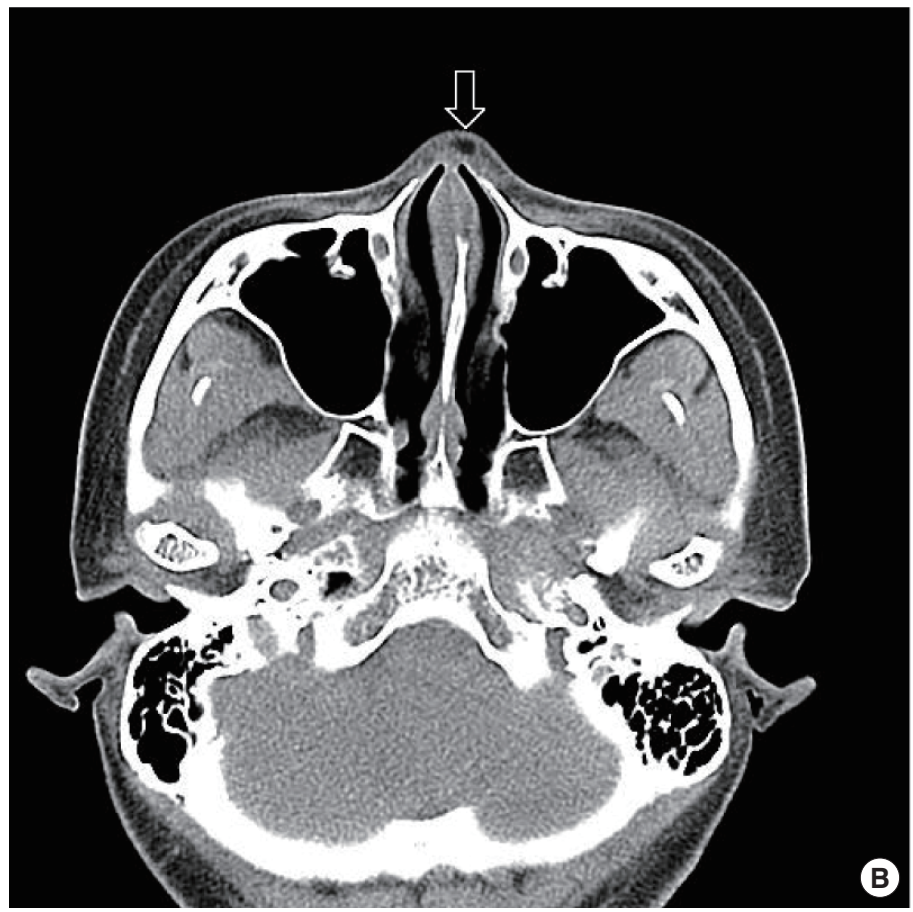

Fig. 2. (A, B) Facial computed tomography showing small, well-defined, hypodense lesions in the superficial layer of the left side of the glabella and both nasal areas (arrows). 

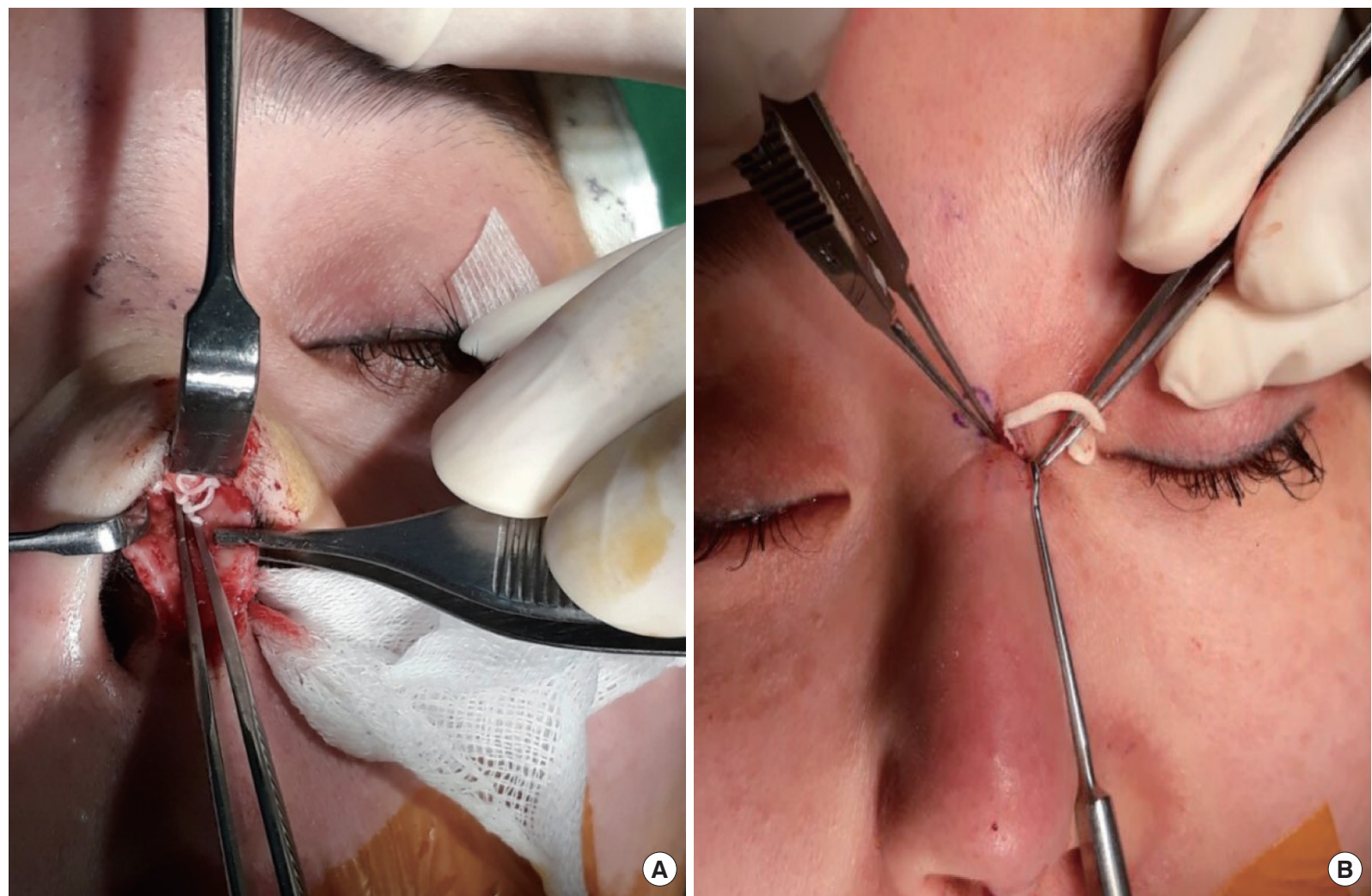

Fig. 3. (A, B) Intraoperative photographs showing the multiple masses found during open rhinoplasty and a skin incision around the glabella.

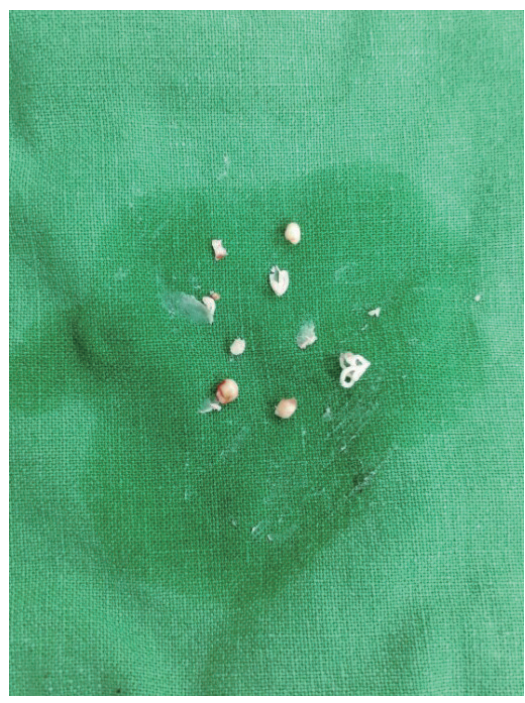

Fig. 4. Photograph showing the smooth extracted granulomas.

lished period.

Multiple epidermal cysts in a patient receiving tacrolimus as an immunosuppressant after kidney transplant were recently reported. Tacrolimus has a similar immunosuppressive action as cyclosporin, and it acts on $\mathrm{T}$ cells to induce keratinization, which can cause multiple epidermal cysts [7]. In our case, we first thought that the granulomas were caused by the filler injection since they occurred near its site. Nevertheless, in rare cases, the masses may be caused by the medications taken by the patient.

Therefore, for patients who are on medications, especially immunosuppressants, clinicians should consider the possibility that granulomas caused by a foreign body reaction may form in an atypical fashion. Future studies with larger sample sizes are needed to obtain clinically significant results. Moreover, it is necessary to consider and differentiate various types of masses that can be caused by the medications taken by the patient. Therefore, in cases involving admission for palpable masses and swelling, the importance of detailed history-taking, including systemic diseases and drug history, should always be kept in mind.

\section{PATIENT CONSENT}

Patient provided written consent for the use of her images.

\section{REFERENCES}

1. Park KG, Dhong ES, Goong SN, et al. Atypical facial filler granuloma: Comparative histologic analysis with paraffinoma. Arch Craniofac Surg 2016;17:169-72. 

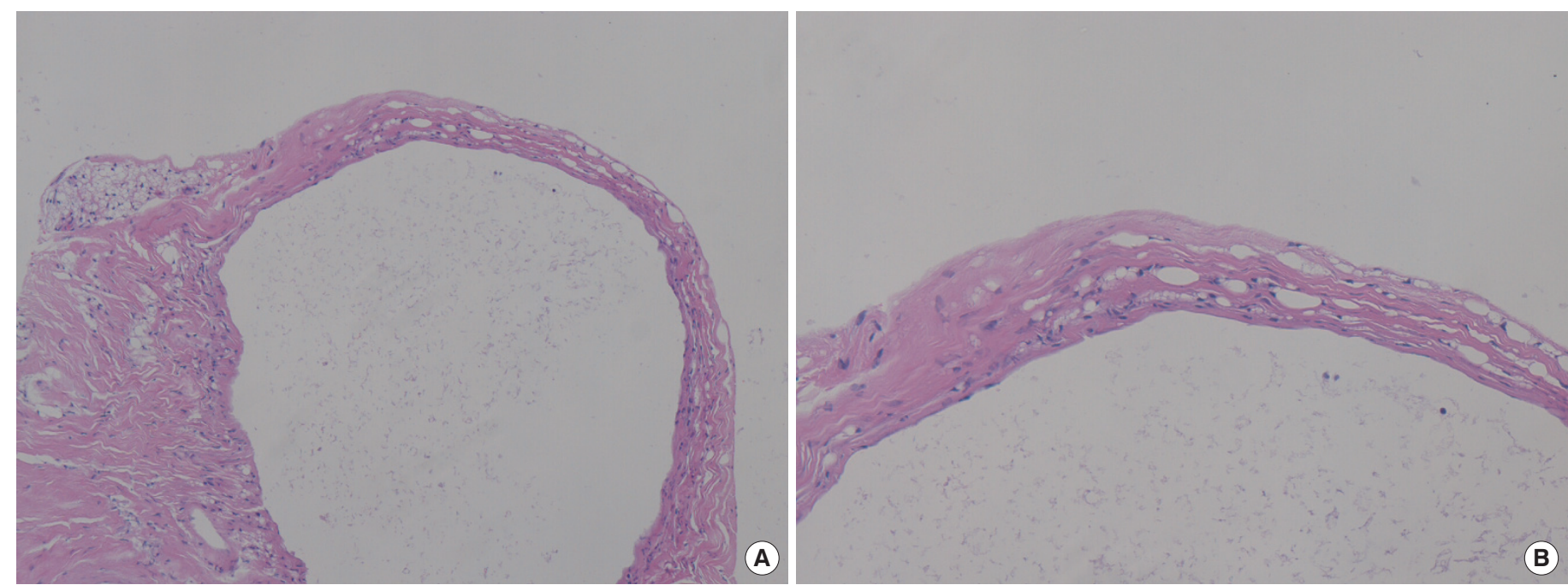

Fig. 5. Light micrograms of the extracted granulomas. (A) Benign cystic lesion consisting of amorphous materials and thin hyalinized collagenous wall (low-power view, hematoxylin and eosin stain [H\&E], ×40). (B) High-power magnification showing mononuclear cells retaining multivacuolated materials in their cytoplasm $(H \& E, \times 100)$.

2. Kim H, Cho SH, Lee JD, et al. Delayed onset filler complication: Two case reports and literature review. Dermatol Ther 2017 Sep [Epub]. http://dx.doi.org/10.1111/dth.12513.

3. Kadouch JA, Kadouch DJ, Fortuin S, et al. Delayed-onset complications of facial soft tissue augmentation with permanent fillers in 85 patients. Dermatol Surg 2013;39:1474-85.

4. Lee JM, Kim YJ. Foreign body granulomas after the use of dermal fillers: pathophysiology, clinical appearance, histologic features, and treat- ment. Arch Plast Surg 2015;42:232-9.

5. Lemperle G, Duffy DM. Treatment options for dermal filler complications. Aesthet Surg J 2006;26:356-64.

6. Baumann LS, Kerdel F. The treatment of bovine collagen allergy with cyclosporin. Dermatol Surg 1999;25:247-9.

7. Ahn IS, Chung BY, Cho SI, et al. Epidermal cysts in a tacrolimus treated renal transplant recipient. Ann Dermatol 2011;23:S182-4. 